\title{
PREVIDÊNCIA SOCIAL, DESENVOLVIMENTO E SOBERANIA ALIMENTAR NO CAMPO BRASILEIRO
}

\section{SOCIAL SECURITY, DEVELPMENT AND FOOD SOVEREIGNTY IN THE BRAZILIAN COUNTRYSIDE}

\author{
Thais Giselle Diniz Santos* \\ Katya Regina Isaguirre-Torres ${ }^{* *}$
}

\begin{abstract}
Resumo: Este artigo resulta de pesquisa realizada no Programa de Pós-Graduação em Meio Ambiente e Desenvolvimento - PPGMADE/UFPR, a qual problematizou a relação entre questão agrária brasileira, trabalho rural e possíveis impactos de alterações do sistema de Previdência Social Especial Rural no Brasil (PSER). A partir do ponto de vista do trabalhador rural brasileiro, buscou-se compreender os impactos da PSER para o desenvolvimento no campo brasileiro, bem como sobre a soberania e segurança alimentar. A compreensão destes impactos propiciou a análise crítica da problemática. Tornou-se importante neste trabalho compreender os impactos socioeconômicos sobre o campo brasileiro das alterações propostas pela PEC n. 287/2016. Entre um dos principais resultados aponta-se que a problematização do trabalhador rural e da Previdência Social Especial Rural perpassa uma interpretação integrada de noções que partem da realidade social, por exemplo, soberania e segurança alimentar e a luta contra a desigualdade social e a exclusão dos povos rurais analisadas neste trabalho, enquanto potências transformadoras dos valores, modos e rumos de produção da vida em sociedade. Tais aspectos podem ser compreendidos como princípios ideológicos de uma movimentação una, forte e diversa com potencial para a construção de uma luta comum, rumo a outro paradigma de desenvolvimento, pautado na verdadeira inclusão e participação social, o qual, entretanto, está em constante construção, devendo ser continuamente reformulado, a fim de propiciar verdadeiro enfrentamento de forças que propiciam a desigualdade, exploração e injustiça. Neste esforço, considerando a complexidade e atualidade do assunto estudado, empregou-se a metodologia de revisão bibliográfica, de análise de dados e documentos.
\end{abstract}

Palavras-chave: Trabalhador rural brasileiro; Previdência Social Especial Rural; Desenvolvimento Rural; PEC n. 287/2016; Segurança e Soberania Alimentar.

Abstract: This article results from a research developed in the Postgraduate Program in Environment and Development - PPGMADE/UFPR, which problematized relation between Brazilian agrarian question, rural work and possible impacts of changes in the

\footnotetext{
* Mestre em Meio Ambiente e Desenvolvimento pelo PPGMADE/UFPR, pesquisadora no grupo de pesquisa EKOA: Direitos, Movimentos Sociais e Natureza. Graduada em Direito pela Universidade Federal do Paraná. Contato: thaisgisellediniz@ gmail.com,

** Professora no Departamento de Direito Público da Universidade Federal do Paraná. Coordenadora do grupo de pesquisa e extensão EKOA: Direito, Movimentos Sociais e Natureza junto ao programa de pósgraduação em Meio Ambiente e Desenvolvimento da UFPR. Pesquisadora colaboradora da unidade de Socioeconomia, Ambiente e Desenvolvimento (SEED), do Departamento de Gestão e Ciências do Ambiente da Universidade de Liège, Campus Arlon. Contato: kisaguirre@gmail.com.
} 
Previdência social, desenvolvimento e soberania alimentar no campo brasileiro

Special Rural Social Security system in the Brazil. From the Brazilian rural worker point of view, it was sought to understand the impacts of the Special Rural Social Security to the Brazilian countryside development, as well as on food sovereignty and security. It has become important in this work to understand the socioeconomic impacts on the Brazilian countryside through changes proposed by the PEC n. 287/2016. Among one of the main results, it is pointed out that the problematization of the rural worker and of the Special Rural Social Security is based on an integrated interpretation of notions that depart from social reality, for example, sovereignty and food security and the struggle against social inequality and exclusion of the rural peoples analyzed in this work, as transformative powers of the values, ways and routes of production of life in society. Such aspects can be understood as ideological principles of a strong and diverse movement with the potential to build a common struggle, towards another paradigm of development, based on a true inclusion and social participation, which, however, is constantly being constructed and must be continually reformulated in order to provide a real confrontation of forces that foster inequality, exploitation and injustice. In this effort, considering the complexity and timeliness of the subject studied, the methodology of bibliographic review, data analysis and documents were used.

Key-words: Brazilian rural worker; Special Rural Social Security; Rural Development; Proposal of constitutional amendment n. 287/2016; Food security and sovereignty.

\section{INTRODUÇÃO}

No contexto de crise paradigmática vivida no Brasil (a englobar vários eixos da vida, tais como natureza, economia, relações sociais e instituições) ganha força uma onda de redução de políticas públicas voltadas à efetivação de direitos sociais. No que atine à Previdência Social, há a tendência de redução de direitos, especialmente mediante o projeto de emenda constitucional n. 287/2016, o qual propõe, entre outras mudanças, que, na prática, a retributividade da Previdência Social Especial Rural passe a ser direta pelo trabalhador rural.

Considerando que a Previdência Social Especial Rural consiste em política complexa e relevante para o desenvolvimento rural brasileiro, buscou-se, como problemática de pesquisa, verificar quais seus efeitos socioeconômicos e ambientais, bem como sua sustentabilidade no sistema de Seguridade Social brasileiro.

A partir do problema a ser estudado, especificamente no meio rural, como resultados verificou-se que as garantias de trabalho digno se relacionam de forma complexa com o meio natural e social. A partir de seu direcionamento e proteção é possível incentivar dinâmicas econômicas e modos de produção da terra, sendo possível impulsionar, ainda que não completamente, outras formas de desenvolvimento, que podem apresentar alternativas à crise paradigmática enfrentada no campo social e ambiental. 
Igualmente, percebeu-se que a PSER para além de constituir um dos principais direitos sociais alcançados pelas trabalhadoras e trabalhadores rurais, trata-se de uma das mais efetivas políticas públicas do campo brasileiro, já que propicia ganhos diretos para a dinâmica econômica em nível local, para a segurança e amparo de trabalhadores rurais desconsiderados pelo arcabouço legal protetivo do Direito do Trabalho Rural, (não empregados), tal como para o incentivo de relações com a terra para além do paradigma produtivista, possibilitando, assim, alternativas socioambientalmente mais equilibradas de desenvolvimento, com base na garantia da soberania e segurança alimentar.

Assim, neste trabalho será demonstrado que tanto os efeitos ao trabalhador em individual, quanto ao tratamento da terra em coletivo são relevantes no incentivo ao desenvolvimento socioambientalmente equilibrado no campo. Parte-se da ideia de que soluções mais amplas para o problema da atual crise socioambiental, que se expressa pela poluição, degradação das florestas, miséria do trabalhador rural entre outros problemas tão presentes no campo brasileiro, passam pela ampliação de direitos sociais, bem como pela superação de um histórico de exclusão e desigualdade.

\section{SEGURIDADE SOCIAL}

No capitalismo o trabalho adquire traços muito específicos, constitui-se dentro da estrutura de mercado e assume natureza de mercadoria, sendo incentivada sua crescente exploração. O capital, devido a sua lógica interna, age orientado por um movimento de valorização do dinheiro investido. Fundado neste viés, em sua etapa concorrencial, marcada pela industrialização e pelo Estado liberal, caracteriza-se pela extração de mais-valia principalmente pelo alongamento da jornada de trabalho (FALEIROS, 2000, p. 93). Diante disso, o capital não atenta quanto a saúde e a duração da vida do trabalhador, visto não ser obrigado a tomar o cuidado pela sociedade (FALEIROS, 2000, p. 59).

Do ponto de vista teórico, a sustentação do capitalismo decorre da suposição de que na estrutura de mercado todo o indivíduo pode ser incorporado por meio do trabalho no capital, mediante o qual recebe um salário que o permitiria satisfazer todas as suas necessidades (dentro do mercado) e, assim, alcançar bem-estar. Nesse modelo, aqueles que não conseguem se incorporar ao trabalho são tidos como incapazes, únicos 
Previdência social, desenvolvimento e soberania alimentar no campo brasileiro

responsáveis pelo seu insucesso, e, por isso, sustentados através de beneficência ou caridade e não de uma política social (CASTRO e LAZZARI, 2016, p. 50).

Para tal visão, própria da teoria liberal, o mercado espontaneamente ocasionaria o equilíbrio entre os indivíduos. Em contraponto, a história demonstrou que o mercado mantém a desigualdade de condições, o que a teoria liberal chama de "falhas do mercado", as quais precisam ser corrigidas com ações fora do mercado (FALEIROS, 2000, p. 27). Ocorre que num cenário de tendências liberais, na medida em que o capitalismo se estabelece e demonstra as mazelas atreladas ao seu funcionamento, a figura do Estado assume papel mais relevante, adquire contornos próprios e passa a possuir como função a proteção social dos indivíduos.

Percebe-se que há um sentido de antagonismo entre capitalismo e proteção da sociedade, pois a proteção social não constitui o sentido do movimento capitalista, já que tal sistema não é concebido para tal, mas sim para o aumento do valor. Somente quando a hegemonia do capitalismo é colocada em risco em razão do seu não cuidado pela sociedade é que surge a necessidade desta proteção social ser oferecida de alguma maneira.

Políticas sociais surgem em diferentes conjunturas, porém todas marcadas pelo confronto entre os interesses das classes dominadas e das dominantes, assumindo contornos específicos que decorrem do desenvolvimento das forças produtivas e também da relação entre as forças políticas. A fim de manter a estrutura econômica pautada na acumulação do capital, o Estado age em prol da legitimação destas estruturas capitalistas junto à população. Para tal adequa o movimento do capital ao movimento social, que luta pela melhoria das condições de vida.

A partir disso, políticas públicas respondem às necessidades do mercado, mas também, sem dúvidas, aos movimentos contestatórios presentes em certa realidade social. Por isso, diversos exemplos de introdução de políticas sociais na história ocorreram em momentos de forte conflito e movimento social. A título de ilustração cita-se o paradigmático caso do seguro-saúde criado por Bismarck em 1883 na Alemanha, quando pairava forte movimentação socialista (FALEIROS, 2000, p. 55).

É justamente nas contradições do modo de produção ao lado das lutas sociais que se possibilita compreender as políticas sociais estatais, bem como a passagem de um Estado Social para um Estado de contenção de direitos sociais. As forças políticas e os interesses das classes definem uma realidade instável na qual se acirram os conflitos, de 
forma que cada vez mais a manutenção da economia capitalista exige maior intervenção do Estado.

Ainda sobre o tema, cumpre destacar que o Estado constitui-se dialeticamente em interação recíproca com as bases materiais do capital, sendo assim, não é simplesmente moldado por fundações econômicas, mas também atua na realidade complexa nas transformações históricas do capital. Assim, é inescapável admitir que no século XX o Estado assume importância no encaminhamento dos problemas sociais e neste viés pode ser ocupado pelos propósitos democráticos sociais, processo constatável pela sucessão de movimentos constitucionais.

A partir da compreensão destes aspectos do Estado é possível aprofundar, do ponto de vista histórico, o surgimento da Previdência Social. Devido à industrialização capitalista, a exploração do trabalho se intensificou de tal maneira que para a perpetuação da forma de produção vigente foi necessário substituir políticas sociais baseadas apenas na assistência e na repressão por formas apoiadas em seguros sociais.

Historicamente, enfraquecidas as estruturas de solidariedade social, em decorrência da exploração própria da etapa da industrialização, foram marcantes as condições de precariedade e de vulnerabilidade dos trabalhadores, o que, conforme já abordado, assumiu visibilidade especialmente no período pós-Primeira Guerra Mundial.

Sem a solidariedade própria dos laços comunitários e em condições precárias, a classe proletária entrou em situação de barbárie, com grande número de trabalhadores acidentados, doentes e idosos sem possibilidades de auferir salário. Situação análoga ocorreu com viúvas e crianças. Nesse quadro, a ideia de política social assumiu seus primeiros contornos.

Na etapa do capitalismo chamada de "concorrencial" a proteção social seguia o modelo de beneficência e caridade particular. O Estado preocupava-se com a livre concorrência e não com as políticas sociais, o que impulsionou o surgimento das primeiras manifestações de intervenção social, marcadas pela ideia de assistência aos pobres e pelo caráter de mutualidade e não de seguro.

A assistência social diferencia-se da noção de seguro. Enquanto na primeira o socorro ocorre depois que a situação de indigência e privação se instalou, na segunda, antecede aos danos, instalando as prestações reparadoras a fim de evitar a situação de privação, até que o indivíduo retorne à condição "normal" de trabalho se for o caso. Quanto a tal ideia de "normalidade" é importante destacar o caráter ideológico que o 
Previdência social, desenvolvimento e soberania alimentar no campo brasileiro

trabalho adquire na sociedade capitalista, transformando-se em critério da vida regular e trazendo o paradigma de sucesso pessoal sobremaneira para o nível econômico. As políticas sociais afirmam a anormalidade daqueles que não podem trabalhar, dando a eles o título de "desadaptados" para o trabalho e sem utilidade para o processo produtivo.

Sendo assim, ainda que a política social tenha raízes no paradigma de solidariedade comunitária, sua função ideológica de reafirmar o trabalho no mercado capitalista, enquanto medida de inclusão social, é inegável, na medida em que destaca a inaptidão do trabalhador em razão de suas condições individuais (saúde, velhice, maternidade) (FALEIROS, 2000, p. 63/64).

A ideia de seguro social começa a se elaborar ao lado da modificação da citada ideia inicial de assistência. O Seguro contra acidentes de trabalho consistiu na primeira espécie de seguro coletivo obrigatória, criado com base no princípio do risco profissional, porém com o fim de reduzir os procedimentos legais, estando os primeiros fundos sob o controle do patrão (FALEIROS, 2000, p. 93/95).

A aposentadoria surgiu no contexto de forte movimento operário nas grandes empresas e voltou-se inicialmente a um regime de capitalização e não de redistribuição de renda. Em condições políticas similares foi implantado o seguro saúde (FALEIROS, 2000, p. 96/101).

A implantação destas políticas sociais, destarte demonstrado por Faleiros, respondeu à conjuntura e às relações de força. De início, conforme indica o autor, caso a pressão popular tenha colocado em risco a dominação econômica das classes dominantes os governos buscaram manter a "paz social", isto é, a aparência de consenso. Para tal o Estado surge como uma figura neutra que age em prol do bem comum (FALEIROS, 2000, p. 88/92).

Quanto maior a força popular, mais relevante é a expansão de políticas sociais. $\mathrm{O}$ autor acima referenciado indica, esparsamente em sua obra, que ao longo da história verificou-se que o mercado tende a adentrar no funcionamento das políticas sociais a partir de uma lógica de mercado, ou seja, visando possibilitar produção de capital dentro do fornecimento de garantias sociais, bem como menor dispêndio econômico. Já os movimentos sociais tendem a ir contra essa tendência, buscando, por exemplo, o controle de caixas de assistência, a não contribuição dos operários, entre outras lutas favoráveis à classe. 
Portanto, nas primeiras manifestações de proteção social predominou o caráter horizontal das políticas sociais, visto que eram os próprios trabalhadores que se organizavam e contribuíam para manter as caixas em prol de sua classe (FALEIROS, 2000, p. 89).

Com a formação do conceito de "bem-estar social", enquanto direito subjetivo a todos assegurado, surge outro modelo de proteção social, qual seja, a previdência social de fato. Com o avançar das ideias ao redor de Estado Social, a previdência assume o caráter público, gerido pelo Estado e com a participação de toda a sociedade. Nas diferentes sociedades, a previdência social parece ter expressado o meio pelo qual o Estado adquiriu o controle da classe operária, porém, contraditoriamente, também resultou de lutas sociais.

Esquematizando as formas de proteção social do trabalhador, acima explicadas, Jean Touchard diferenciou quatro fases evolutivas, sendo elas: $1^{\text {a }}$ ) Experimental - marcada pelas primeiras normas nos países europeus relacionadas aos acidentes de trabalho e à invalidez; 2 $2^{\mathrm{a}}$ ) Consolidação - caracterizada pela constitucionalização dos direitos sociais, pelo modelo de capitalização em modelos de poupança compulsória e pela experiência norte americana do New Deal; $3^{\text {a }}$ ) Expansão distinta pelo período pós-Segunda Guerra Mundial, pela disseminação das ideias de Keynes e pelo aprofundamento das propostas de Beveridge; $4^{\mathrm{a}}$ ) Redefinição - definida pelo avanço neoliberal e pela contenção de direitos sociais (CASTRO e LAZZARI, 2016, p. 63).

Quanto aos Direitos Sociais especificamente no Brasil, a economia de mercado foi introduzida pelo colonizador e baseou-se na extração das riquezas da terra e na destruição dos sistemas de vida coletiva indígena, visando o lucro comercial com base na monocultura, no latifúndio, no mercado internacional e na submissão da classe não capitalista a uma condição subalterna, isto é, excluída da condução do processo produtivo. Esse modelo de exploração seguiu-se por longo período da história brasileira, perpetuando-se a exclusão dos trabalhadores da terra, a exploração da natureza e o modelo agrocomercial de economia.

Foi com a crise de 1930 que mudanças mais paradigmáticas se passaram no cenário brasileiro de políticas sociais, quando ocorreu a crise da oligarquia agrocomercial, formou-se um proletariado industrial majoritariamente constituído por imigrantes e fortaleceu-se uma burguesia industrial e as massas passaram a se concentrar em cidades. 
Previdência social, desenvolvimento e soberania alimentar no campo brasileiro

Tais mudanças demandaram o desenvolvimento interno a partir de ação estatal mais efetiva, a fim de fortalecer o comércio e a indústria (FALEIROS, 2000, p. 116/117). Do contexto de crise nos anos 1930, decorreu forte luta social, às quais os seguros sociais visaram apresentar uma resposta.

Nesse contexto brasileiro, os seguros sociais foram implantados muito aos poucos, de cima para baixo, baseados na repressão, com o objetivo precípuo de reduzir os conflitos sociais, exercendo assim função organizativa da classe operária, sem permitir melhorias quanto à exploração do trabalho, mas garantindo apenas sua guarda, para, baseado no princípio do risco, permitir o controle da classe operária insatisfeita, tal qual a melhoria de seu poder aquisitivo (FALEIROS, 2000, p. 122/123).

\section{SEGURIDADE SOCIAL NO BRASIL}

No contexto do surgimento dos direitos sociais estabeleceram-se dois principais sistemas de seguridade social, o chamado beveridgeano, ou de repartição, no qual: “[...] toda a sociedade contribui para a criação de um fundo previdenciário, do qual são retiradas as prestações para aqueles que venham a ser atingidos por algum dos eventos previstos na legislação de amparo social” (CASTRO e LAZZARI, 2016, p. 66), bem como o chamado bismarckiano, ou de capitalização, no qual "somente contribuíam os empregadores e os próprios trabalhadores empregados, numa poupança compulsória, abrangendo a proteção apenas destes assalariados contribuintes" (CASTRO e LAZZARI, 2016, p. 66). Nesse último modelo a noção de solidariedade não atinge a todos, somente aos contribuintes (CASTRO e LAZZARI, 2016, p. 65).

Com inspiração nos sistemas supracitados, existem modelos contributivos, no qual pessoas especificadas na legislação ficam obrigadas a contribuir para o regime, ou seja, o custeio ocorre diretamente; bem como modelos não contributivos, nos quais a destinação ocorre via arrecadação tributária geral, sem contribuintes especificados e custeio direto.

O Brasil adota predominantemente o sistema bismarckiano, porém é composto por um modelo misto, o qual comporta o custeio direto e especificado no que diz respeito à previdência social geral e no que atine à assistência social e à Previdência Social Especial Rural adota sistema indireto de custeio, isso é, universal, de base não contributiva, seletivamente em relação aos indivíduos que se enquadrem na caracterização legal. 
Nos termos da CRFB (art. 195, caput): “A seguridade social será financiada por toda a sociedade, de forma direta e indireta, nos termos da lei, mediante recursos provenientes dos orçamentos da União, dos Estados, do Distrito Federal e dos Municípios (...)"(BRASIL, 1988). Portanto, as fontes de custeio da Seguridade Social são diversificadas, provenientes de recursos dos Orçamentos da União, estados e municípios e das contribuições sociais. Nesse sentido dispõe o art. 195, § $1^{\circ}$ que: "As receitas dos Estados, do Distrito Federal e dos Municípios destinadas à seguridade social constarão dos respectivos orçamentos, não integrando o orçamento da União” (BRASIL, 1988).

Além disso, segundo $\S 2^{\circ}$ do mesmo artigo: "A proposta de orçamento da seguridade social será elaborada de forma integrada pelos órgãos responsáveis pela saúde, previdência social e assistência social, tendo em vista as metas e prioridades estabelecidas na lei de diretrizes orçamentárias (...)" (BRASIL, 1988).

Tencionando tais bases do atual sistema de proteção social, cabe trazer brevemente alguns elementos sobre o seu desenvolvimento no Brasil, a qual partiu desde um sistema assistencialista, passando pelo seguro social, até a formação da Seguridade Social com base no princípio da universalidade.

Inicialmente, vigia um sistema esparso de regulamentação de política social, surgindo a expressão "previdência social” apenas na Constituição de 1946, em substituição do até então predominante “seguro social”. Percebe-se que até 1930 inexistia uma legislação social sistemática, considerando que apenas a partir desta época se concretizou o capitalismo industrial no país, de forma a passar a hegemonia oligárquica para a burguesa.

Getúlio Vargas, então presidente, visou acompanhar as mudanças econômicas do pós-guerra, lidando com a ampliação do mercado interno e com os interesses da burguesia industrial ascendente, tal como permanecendo na defesa dos interesses da oligarquia (FALEIROS, 2000, p. 124/130).

Nessa época, a política social foi implantada de maneira gradativa, centralizada e fragmentada, na medida da necessidade de garantir o controle da classe trabalhadora no contexto de crise. A continuidade do processo de industrialização e urbanização do país precisava desta regulamentação do trabalho.

Com mesmo viés, em 1931 foi criado o Departamento Nacional do Trabalho dentro do Ministério do Trabalho, Indústria e Comércio, com o objetivo de promover medidas de Previdência Social. Pelo Decreto n. 20.465 institui-se quota de participação 
Previdência social, desenvolvimento e soberania alimentar no campo brasileiro

do Estado na previdência social e em 1934 surgem o Conselho Superior de Previdência Social e o Departamento de Previdência Social (ALVIM, 2014, p. 11/13).

Em 1945, foi criado um marco do Direito Previdenciário Brasileiro, o Decreto Lei n. 7.526, importante por uniformizar previdência social brasileira, ainda que somente em relação aos trabalhadores urbanos, excluindo os rurais. A Lei Orgânica da Previdência Social, Lei n. 3.807, somente foi aprovada em 1960, trouxe maior inclusão aos trabalhadores urbanos e padronizou o sistema, porém mantendo a exclusão dos trabalhadores rurais, tendo em vista os interesses da oligarquia.

Destarte ora tratado, nos anos seguintes o Brasil foi cenário de luta política mais geral, inclusive dos trabalhadores rurais, e o golpe de 1964 foi resultado também do medo relacionado a tais lutas como ameaça às classes dominantes (FALEIROS, 2000, p. 157).

Em 1966, por meio do Decreto-Lei n. 72, todos os institutos de previdência social foram integrados no INPS, transformado em Ministério em 1974. Este viés centralizador demonstrou que as políticas de previdência social visavam primordialmente apaziguar as tensões sociais e a insatisfação dos trabalhadores, que colocariam em risco a segurança nacional.

A Lei n. 6.439 de 1977 instituiu o SINPAS (Sistema Nacional de Previdência e Assistência Social), dividido em Instituto Nacional de Previdência Social (INPS), Instituto Nacional de Assistência Médica da Previdência Social (INAMPS), Fundação Legião Brasileira de Assistência (LBA), Fundação Nacional do Bem-Estar do Menor (FUNABEM), Empresa de Processamento de Dados da Previdência Social (DATAPREV), Instituto de Administração Financeira da Previdência Social (IAPAS) e Central de Medicamentos (CEME). Em 1984 foi criada a Consolidação das leis previdenciárias.

A Constituição de 1988 tratou da Seguridade Social em capítulo próprio (arts. 194 a 204), dispondo que a Seguridade Social é gênero que engloba Previdência Social, Assistência Social e Saúde. Nos termos do texto magno (art. 194): “A seguridade social compreende um conjunto integrado de ações de iniciativa dos Poderes Públicos e da sociedade, destinadas a assegurar os direitos relativos à saúde, à previdência e à assistência social" (BRASIL, 1988).

Em 1990, foi criado o INSS, autarquia que substituiu o INPS e o IAPAS e assumiu as funções de arrecadação, fiscalização, cobrança, aplicação de penalidade e 
regulamentação da matéria. A Lei n. 8.080/1990 versou sobre a saúde; a Lei n. 8.212/1991 sobre o custeio do sistema de seguridade social; a Lei n. 8.213/1991 sobre os benefícios previdenciários e o Decreto n. 3.048/1999 regulamentou essas normativas. A Lei n. 8.742/1993 tratou da organização da assistência social.

Este breve retrospecto denota que a sistematização do Direito Previdenciário e de suas instituições no Brasil foi ao sentido de se aproximar cada vez mais do modelo de bem-estar social. Em seguida, a fim de adentrar especificamente no tema da Previdência Social Especial Rural, busca-se, considerando todo o exposto até o momento, entender o funcionamento do sistema de Previdência Social adotado no Brasil.

\section{UM BREVE SUBSTRATO TEÓRICO SOBRE O MODELO BRASILEIRO DE SEGURIDADE SOCIAL}

No sistema de Previdência Social brasileiro existem múltiplos regimes, porém, todos são de filiação obrigatória, já que "únicos" quanto a cada um dos grupos de indivíduos protegidos (CASTRO e LAZZARI, 2016, p. 92). Esse modelo possui três pilares: 1) Previdência Social Básica: pública, compulsória em forma de repartição, com financiamento misto, com regime geral financiado pela União e Regimes Próprios de Previdência dos Servidores, 2) Previdência Complementar: privada, em regime de capitalização, 3) Assistência Social: para idosos e portadores de necessidades ou cuidados especiais, abrangendo as pessoas que estejam carentes de condições de subsistência (CASTRO e LAZZARI, 2016, p. 91/92).

Neste sistema de pilares, a solidariedade social e a redistribuição de renda são fundamentais, já que o pilar público e obrigatório é preponderante para todos que se submetem ao regime geral, independentemente de nível de renda, ainda que seja possível a aderência à previdência complementar privada.

Enquanto fontes formais do Direito Previdenciário brasileiro, ou seja, normas que regerão juridicamente de forma legítima e cogente esse sistema social citam-se: 1- A Constituição Federal; 2- As Emendas à Constituição, espécies legislativas decorrentes do exercício do chamado Poder Constituinte derivado; 3- As leis infraconstitucionais, a incluir as leis complementares, as leis ordinárias, as leis delegadas, as medidas provisórias e os decretos legislativos; 4- Atos administrativos (realizados através de órgãos ou entidades da Administração Pública), a abarcar decretos regulamentadores, portarias, instruções normativas, ordens de serviço dos Ministérios e pareceres normativos; 5- 
Previdência social, desenvolvimento e soberania alimentar no campo brasileiro

decisões judiciais, as quais consistem em fontes formais exclusivamente no que tange às decisões definitivas do Supremo Tribunal Federal nas ações diretas de inconstitucionalidade ou nas ações declaratórias de constitucionalidade. Os costumes, a doutrina e a equidade são considerados fontes informais do Direito Previdenciário.

Em relação aos princípios fundamentais deste ramo jurídico denotam-se dois presentes no sistema de regulamentação da previdência social brasileira, quais sejam, o princípio da solidariedade, como a noção de bem-estar coletivo na medida da proteção de toda a coletividade e o princípio da vedação do retrocesso social, caracterizado na impossibilidade de redução das implementações de direitos fundamentais operadas.

Ainda, a CRFB consigna especificamente os seguintes princípios em seu art. 194, Parágrafo único: 1- Princípio da Universalidade de Cobertura e do Atendimento; 2 Princípio da Uniformidade e Equivalência dos Benefícios e Serviços às populações Urbanas e Rurais; 3- Princípio da Irredutibilidade do valor dos benefícios, o qual equivale ao da intangibilidade do salário; 4- Princípio da Equidade na forma de participação no custeio, no sentido de garantir participação equitativa de trabalhadores, empregadores e Poder Público no custeio da seguridade social; 5- Princípio da Diversidade de base de financiamento, que visa garantir a existência de várias fontes pagadoras, não adstrita aos trabalhadores, empregadores e Poder Público, por exemplo, a partir da receita de concursos de prognósticos e do CPMF; 6- Princípio do caráter democrático e descentralizado de administração, do qual decorre que a gestão deve ser feita mediante discussão com a sociedade, sendo, para isso, criados órgão colegiados de deliberação.

\section{O TRABALHADOR RURAL NA PREVIDÊNCIA SOCIAL BRASILEIRA}

Os principais aspectos da Previdência Social no Brasil, acima esboçados, permite a compreensão do funcionamento e dos princípios que regem a Previdência Social Especial Rural. Como se trata de política social voltada ao trabalho rural considerado em sua diversidade, faz-se necessário esclarecer como a política entende a especificidade deste sujeito trabalhador rural categorizado como segurado especial.

Sem dúvidas, os movimentos sociais dos trabalhadores do campo foram importante elemento de pressão na abrangência de políticas sociais para os trabalhadores rurais. O Estatuto do Trabalhador Rural, Lei n. 4.214 de 1963, consistiu em marco no alcance de garantias fundamentais do trabalhador rural. Mediante este regramento parte relevante da legislação trabalhista foi estendida ao campo (DELGADO, 2016, p. 431). 
Isto posto, a doutrina afirma que existe um regime ao trabalhador rural anterior ao ETR e outro posterior. Com o Estatuto do Trabalhador Rural foram estendidos os direitos trabalhistas ao empregado rural. Enquanto a CLT definia o empregado rural pelo método de trabalho e finalidade das atividades em que estivesse envolvido, o critério jurídico no Brasil pautava-se no segmento de atividade do empregador para tal definição.

O ETR sedimentou o critério do segmento de atividade do empregador na definição do empregado rural, o que foi seguido pela Lei de Trabalho Rural (n. 5.889/1973). Com base em situações concretas outro critério é estabelecido pela ordem jurídica, qual seja: o local de prestação laborativa, ideia que vem também insculpida na Lei de Trabalho Rural, quando trata de labor em imóvel rural ou prédio rústico. Atualmente esses são os dois elementos fático-jurídicos especiais do emprego rural (DELGADO, 2016, p. 434/436).

Ainda que seja considerada a relevância da abrangência das garantias trabalhistas ao empregado rural no plano legislativo, um problema fático que se apresentou, e tende a se acentuar, é que a maior parte do trabalho rural no Brasil não possui as características aptas a caracterizá-lo enquanto "emprego".

A minoria dos trabalhadores rurais condiz com a figura do "emprego formal". Por isso, diz-se que o âmbito do ETR em que se deparou maior impacto social foi na previdência social, isso porque permitiu a inclusão do trabalhador rural, em uma visão ampla de sua caracterização, ou seja, considerando a diversidade das formas de trabalho, para além da figura do emprego formal.

Destaca-se que a inclusão de agricultores não assalariados ao sistema de direitos sociais, como uma categoria especial, independente de contribuição, é parte de antiga luta pela definição de "trabalhador rural" (BARBOSA, 2007, p. 259). Nesse conceito foram incluídos todos os que trabalham na terra, mesmo que não assalariados, pela figura do "segurado especial".

No que atine à Previdência Social, o ETR apenas foi regulamentado em 1972, com a Lei Complementar n. 11, de 25.05.1971, que criou o Plano de Assistência ao Trabalhador Rural - Prorural, regulamentado pelo Decreto n. 69.919, de 11.01.1972, e o FUNRURAL. A partir daí, passou a existir concretamente proteção mais ampla da dignidade dos trabalhadores rurais em sua diversidade, não limitada apenas à relação de emprego, isto é, incluindo parceiros, arrendatários, posseiros e pequenos proprietários rurais, desde que não fossem essencialmente empregadores. 
Previdência social, desenvolvimento e soberania alimentar no campo brasileiro

De início, apenas um membro da família tinha direito de acessar o Prorural. Assim, esse era um direito do "chefe da família", geralmente o homem. Neste momento, às mulheres trabalhadoras rurais era garantida apenas a qualidade de dependente, o que lhes proporcionava o direito à pensão, quando do falecimento do esposo trabalhador rural. Além de as mulheres serem excluídas do benefício, pairava disparidade em relação ao trabalhador urbano, já que o valor dos benefícios correspondia a apenas $50 \%$ do salário mínimo e 30\% no caso de pensão (CUNHA, 2009, recurso eletrônico).

Com a Constituição Federal de 1988 houve maior concretização do acesso à previdência social por parte dos trabalhadores rurais, já que estendeu a esta categoria a garantia de benefício previdenciário no valor do salário mínimo e de acesso às mulheres. Mesmo assim, sua implantação dependeu, de início, de ações judiciais individuais e apenas em 1991 pautou-se em legislação ordinária (Lei n. 8.213/1991) e decretos regulamentadores.

A vinculação do piso previdenciário ao salário mínimo, ocorrido com a Constituição Federal de 1988, consistiu em importante passo no combate às desigualdades de renda e à pobreza no Brasil. No que atine à população rural, o impacto foi relevantíssimo, já que, à época, a média da renda dos trabalhadores rurais era bastante inferior a dos trabalhadores urbanos. Dados do Índice de Gini indicam, nesta via, que o aumento do salário mínimo no Brasil foi indiretamente proporcional à desigualdade de renda $^{1}$ (CONTAG, 2016, p. 26).

\section{A IMPORTÂNCIA DA ABRANGÊNCIA DO SEGURADO ESPECIAL PARA O DESENVOLVIMENTO NACIONAL EQUITATIVO E INCLUSIVO}

São notáveis as condições de subalternidade e exclusão às quais os povos rurais foram submetidos ao longo da consolidação de um desenvolvimento em sentido capitalista no Brasil, iniciada a partir da colonização europeia. Entende-se que tais condições possuem permanência até os tempos presentes.

A realidade rural brasileira é marcada pelo clássico quadro de concentração de terras, trabalho escravo, devastação ambiental e de contínuo ataque aos direitos à terra e aos territórios de camponeses, indígenas e quilombolas (ISAGUIRRE-TORRES e FRIGO, 2013. p. 07.). Ao lado dessas velhas condições no campo, segundo apontado por James Scott, uma característica das transformações agrícolas consiste no fato de que 
removem os pobres do processo produtivo, ao invés de inseri-los mediante a exploração direta (SCOTT, 2002, p. 12).

No Brasil, os trabalhadores, especialmente os rurais, ficaram à margem e "redundantes" dentro do modelo dominante de produção. Esta característica faz parte da história agrária do país e deve ser encarada a fim de vislumbrar cenários futuros mais inclusivos e equitativos.

Defende-se a existência de um ponto de união entre os povos da terra no Brasil, evidentemente dentro de uma diversidade muito grande, porém capaz de trazer relevância para a diferenciação em conjunto desses atores sociais. A categoria "trabalhador rural brasileiro" é defendida neste trabalho enquanto espectro de atores do campo que são expropriados pelo capital, ou/e sofrem ameaça de sê-lo, que trabalham, de alguma maneira, atrelados à ruralidade e à natureza, e, além disso resistem à exploração do trabalho e da natureza, em uma luta diária caracterizada pela busca por permanecer na terra e em condições dignas de trabalho familiar e/ou comunitário e, consequentemente, de vida.

Portanto, a categoria "trabalho rural" aqui utilizada decorre do sentido mais abstrato de trabalho, enquanto ação humana sobre a terra a fim de possibilitar os meios de vida em comunidade. Tendo este sentido em vista, percebe-se que este trabalho rural consiste, em certa medida, no processo natural entre ser humano e seu meio, por isso é essencial para caracterizar os povos mais remotos não apenas no Brasil.

Os trabalhadores rurais, nesse recorte, consistem em povos e comunidades que vivem em relação direta com a natureza enquanto base de sua produção material e social, com organização social fundada nas relações familiares, de parentesco e na convivência coletiva. No Brasil, pelo histórico de ocupação em seu largo território, a diversidade desses povos é tão ampla que mesmo a partir de um aprofundado trabalho antropológico seria provavelmente impossível citar todas as diferentes realidades e raízes existentes.

Ademais, enquanto povos humanos, trabalhadores rurais vivem meio à constante reformulação de seu modo de vida, o que por vezes modifica sua autodeterminação identitária, incrementando ainda mais essa diversidade. À vista disso, mesmo que sejam apresentadas várias denominações clássicas dos povos da terra brasileiros, se estará longe de seu esgotamento. Como designações mais comuns, citam- 
Previdência social, desenvolvimento e soberania alimentar no campo brasileiro se: “quilombolas", "indígenas”, "seringueiros"; "pescadores"; “castanheiro"; “caiçaras”, entretanto muitos outros poderiam ser mencionados.

O trabalhador rural brasileiro é constituído a partir dessa diversidade, estando dentro de uma dessas autodeterminações ou descendendo de alguma maneira delas. Em contraponto a isso, a formação do Brasil enquanto um Estado, nos moldes modernos, pressupôs a determinação de diversos elementos de identificação, em especial uma ideia única de nação, baseada em uma língua e cultura unificadas por uma nacionalidade específica, a brasileira. Sobre o conceito de nação Paulo Bonavides indica que esta consistiria em uma identidade de crenças, costumes, tradições, aspirações, ideias, reivindicações, pelas quais uma coletividade humana faz a sua história (CARVALHO, 2013, p. 483).

Esta unificação cultural representada pela imposição de uma ideia única de nação brasileira decorreu da imposição de um modelo cultural e econômico muito específico, qual seja, o da sociedade industrial moderna, bem como a exclusão das nações que neste território conviviam, em torno da sobreposição de uma língua e cultura oficiais. Uma língua determina um modelo de representação do "universo". Em outros termos, privilegiar uma língua é impor um modelo de representação única e é, por isso mesmo, homogeneizar o sistema de informações (CARVALHO, 2013, p. 483).

Sendo assim, criar uma nação brasileira única significou sobrepor valores e traços culturais como oficiais, assim como converter diversos territórios, povoados por diversas culturas e línguas, em um território capitalista no contexto mundial.

Como consequência do Estado capitalista decorreu a centralização política, a partir de uma só nação, uma só lei, um só interesse nacional de classe, sendo estabelecida a livre concorrência e a supremacia econômica e política da classe burguesa (MARX \& ENGELS, 1999, p. 16). Este modelo de instituição foi o qual se buscou forçosamente incutir no território brasileiro.

Tendo em vista tal cenário de busca pela instituição do interesse de uma parte da população como dominante e subjugar outra parcela dela, aumenta a importância de relatar a existência dos povos da terra que fizeram e fazem parte da história do território hoje identificado como Estado brasileiro.

Prevalece a ideia de hegemonia, a qual consiste na luta pela universalização de uma perspectiva particular, que se espalha através do Estado. Para os povos rurais, além dos efeitos nocivos físicos, há efeitos indesejados do ponto de vista simbólico, que 
são tão importantes quanto os físicos. Dessa forma, quanto menos integrados diretamente às relações capitalistas, mais esses povos são empurrados por processos de empobrecimento causados em grande medida pela mundialização da economia.

Neste cenário, as políticas integracionistas visam transformar cada pessoa em trabalhador individual e com isso acabar com o povo e liberar o território, que ao estar vazio se transforma em uma mercadoria mais interessante para venda (SOUZA FILHO, 2015. p. 66). Por isso, afirma-se que os povos da terra e sua cultura são entendidos no desenvolvimento capitalista enquanto meros obstáculos a serem destruídos e invisibilizados.

O conflito entre o desenvolvimento capitalista e os povos rurais ou da terra aparece rapidamente no que se refere à concepção de terra: enquanto para os povos da terra implica em pertencimento, para o mundo capitalista virou uma mera mercadoria, conforme bem esclarece Carlos Frederico Marés de Souza Filho, a cultura proprietária moderna e capitalista busca restringir a percepção da terra à ideia de mercadoria, a partir do que o valor da terra é maior quanto mais vazia esta esteja, sem povos, animais e florestas, isto é, estéril e sem impedimentos para o livre desenvolvimento capitalista (SOUZA FILHO, 2015. p. 57).

A terra virou mercadoria e logo capital. O capitalismo mudou o conceito de utilidade da terra, pois se para os povos a terra era fonte de vida, para o modelo capitalista a terra se transformou em mercadoria que se compra, vende e acumula. Como capital, a terra sequer necessita produzir para ter valor, basta estar disponível e assim surge um problema: "tudo o que está em cima dela atrapalha" (SOUZA FILHO, 2015. p. 08).

Essa marginalização das comunidades tradicionais e busca por manter a "terra vazia" (já que ela é mercadoria) criou uma guerra contra a natureza e os povos que a ocupavam (SOUZA FILHO, 2015. p.62 e 64).

Nessa toada, uma das principais controvérsias vividas atualmente pelos povos chamados tradicionais ${ }^{2}$ é que a existência deles é atrelada a um parque, reserva ou floresta, então se confunde o território pertence ao povo ou à natureza em si. Marés de Souza Filho afirma que tecnicamente são territórios dos povos e não da natureza, porque a natureza só está preservada porque os povos a preservam (SOUZA FILHO, 2015. p. $62 / 64)$

Embora tais povos venham se contrapondo ao desenvolvimento predatório voltado à perpetuação do modo capitalista de desenvolvimento, mudanças estruturais são 
Previdência social, desenvolvimento e soberania alimentar no campo brasileiro

contidas, o que gera soluções parciais, mas mantendo o modo de produção e o regime de propriedade, bem como a estrutura de dominação e a hegemonia (HACON; LOUREIRO, 2014. p.61). A luta destes povos se contrapõe ao sistema hegemônico, mas não se concentra em mudanças totais ou estruturais e sim em soluções específicas a fim de permitir sua existência e não modificar o status quo de modo geral.

De qualquer maneira, mesmo diante de grande adversidade enfrentada (avanço violento sobre suas terras e mesmo violações físicas) esses povos sobrevivem e demonstram que a ideia de um único modelo de desenvolvimento, pautado na monetarização da natureza, não trouxe soluções para o desequilíbrio socioambiental, nem deu fim aos diferentes modos de vida. Ainda que estes modos de vida não se apresentem, por ora, voltados a transformações totalizantes, demonstram que ao se proteger a diversidade cultural protege-se a natureza que dela faz parte num processo dialético.

Nesse sentido, segundo Ianni (2013, p. 143) o caráter revolucionário dos movimentos sociais do campo não advém apenas do posicionamento contrário ao latifúndio, mas na "rearmação da comunidade", na defesa da vida e do trabalho.

Ou seja, ainda que diante de severas adversidades, os povos da terra persistem, resistem e demonstram que não estão rumo ao desaparecimento e ao colapso, em contraponto ao atual sistema hegemônico, o qual permanece em crise, distante de soluções transformadoras.

Assim, prova-se que os povos da terra não devem ser protegidos somente para manter as florestas, nem que os agricultores familiares devem ser incentivados apenas em prol da soberania alimentar, mas sim que sociedade e natureza formam uma totalidade em relação direta e que modelos mais equilibrados são construídos mediante processos inclusivos, verdadeiramente participativos, voltados para a vida materialmente digna em sociedade, para além da acumulação constante, e desigual, de riquezas.

A crise econômica que se iniciou em 2007, causando um colapso nas instituições financeiras, a eclosão da bolha imobiliária e a recessão das bolsas de valores, principalmente nos países do centro do capitalismo, tiveram sérias consequências a nível mundial em termos de desaceleração da economia e disponibilidade de crédito. Ao mesmo tempo, muitos países da periferia (nos quais os latino-americanos dos governos progressistas consistem em exceção parcial) registraram significativo aumento da pobreza (ESCOBAR, 2014, p. 35). Ainda vale mencionar, a crise ambiental, a migratória e seus impactos. 
Diante disso, as instituições do capitalismo financeiro tentam encontrar saídas através das mesmas estratégias convencionais para impulsionar a competitividade das exportações, evidenciando que não possuem novas ideias para enfrentar a problemática do desenvolvimento. Visões de povos que resistem na terra mostram que é possível construir outro mundo: sem fome, com soberania alimentar, com o respeito à vida e à natureza. Somente vivendo de maneira diferente é possível construir outra realidade socioambiental.

Evidentemente, considerando que a história é algo construído, não é possível que um paradigma seja abandonado e outro construído repentinamente, porém ações inclusivas de outros modos de enxergar o mundo são essenciais na possibilidade de vislumbrar novos caminhos. Incluir e não invisibilizar é o caminho para serem criadas alternativas, bem como afastar a violência e possibilitar avanços no presente.

Políticas públicas de incentivo aos trabalhadores rurais, como é a Previdência Social Especial Rural, geraram melhoria da qualidade de vida não só da parcela populacional a qual se destina, mas a todos os brasileiros. Conforme analisar-se-á, incrementa a igualdade social, incentiva a produção alimentar, entre outros resultados socialmente inclusivos.

A PSER assume grande importância no estímulo do modelo de produção alternativo ao convencional, e mais adequado, pois para além de um direito, constitui uma política pública para os trabalhadores rurais em regime de produção diferenciado. Para além de gerar benefícios aos agricultores, esta política social vem gerando avanços em termos equitativos em nível local e nacional, com melhoria do nível de vida especialmente em municípios empobrecidos, bem como a partir de incentivo a modo de produção mais adequado socioambientalmente.

Itera-se que a PSER abarca os trabalhadores rurais na sua diversidade, incluindo "indígenas", "pescadores artesanais" e assemelhados, "agroextrativistas" e "povos e comunidades tradicionais" em geral, o que é importante na medida em que reconhece um trabalho para além da relação de produção de capital, tirando da invisibilidade o fato de que esses sujeitos trabalham. Tal trabalho, pelo qual reproduzem suas vidas, merece proteção, já que a dignidade é um direito de todos.

Além disso, enquanto comunidades não pautadas na individualização do trabalho e no assalariamento, os benefícios previdenciários assumem um papel relevante na melhoria das condições de vida, a partir de incremento de renda, não só dos 
Previdência social, desenvolvimento e soberania alimentar no campo brasileiro

trabalhadores em individual, mas de toda a comunidade. Este contexto propicia melhoria da vida de uma comunidade como um todo a partir de um benefício fornecido, em tese, ao indivíduo.

Assim, referida política social permite a garantia de renda a estes grupos em coletivo, o qual é investido na qualidade de vida e na produção da comunidade, propiciando que possam continuar se reproduzindo e protegendo seus modos de vida e cultura, incentivando o equilíbrio dessas formas de vida e sua perpetuação. A PSER atua no reconhecimento da dignidade desses grupos, os quais sofrem com as adversidades de um sistema produtivo que tenta a eles se sobrepor.

Considerando o histórico avanço do modo de vida hoje hegemônico sobre povos da terra, o benefício previdenciário torna-se importantíssimo para a permanência de seus modos de vida, os quais já se encontram dentro do capital. Ou seja, seus modos de vida foram e são fortemente impactados pelo sistema capitalista, de tal maneira que não há como negar sua dependência, dentro desse sistema, de renda para garantia de vida digna.

Entretanto, no contexto de crise vivida no Brasil, expressa pelo esgotamento do sistema capitalista arquitetado neste país, ocorre uma onda de redução de políticas públicas voltadas à vida sociambientalmente equilibrada. No que atine à previdência social, há a tendência pela redução de direitos, conforme demonstra recente Proposta de Reforma Previdenciária. Portanto, aprofundada a importância da Seguridade Social em sentido amplo e da previdência social que incluiu os trabalhadores rurais, tanto quanto à dignidade humana quanto ao desenvolvimento socioambiental inclusivo e equitativo, cabe analisar especificamente os riscos de restrições nestas garantias sociais.

\section{A PREVIDÊNCIA SOCIAL ESPECIAL RURAL, O DESENVOLVIMENTO RURAL E A SEGURANÇA E SOBERANIA ALIMENTAR}

Desde que o regime especial de previdência social passou a se aplicar aos trabalhadores rurais brasileiros, vários estudos foram realizados a fim de constatar suas consequências e efeitos socioeconômicos para a sociedade brasileira.

A CRFB assegura a proteção previdenciária especial aos trabalhadores/as da economia familiar rural, considerando os indicativos de que estes vivem abaixo da linha da pobreza e atuam no setor informal, portanto com baixa capacidade contributiva (A 
aposentadoria especial volta-se às famílias entre aquelas com a menor renda no país. Segundo pesquisas levantadas pelo FIAN Brasil a aposentadoria rural equivalia a $70 \%$ da renda familiar de mais da metade das famílias atendidas pela Previdência Rural, contribuindo para, pelo menos, 1/3 da redução da pobreza entre 2005 e 2014 (FIAN, 2017, p. 20):

Pela participação que a aposentadoria rural especial assume na renda das famílias agricultoras e pela faixa de renda destas famílias, percebe-se que se trata de uma medida de combate à fome e à pobreza, permitindo melhor qualidade de vida e saúde a essas famílias, as quais, com acesso a maior renda, vivem melhor no campo e ali permanecem. Portanto, tal política contém o êxodo rural, além disso, permite dinamizar as vidas e o trabalho dos rurícolas, o que incentiva a melhor produção para si e para o comércio.

Conforme dados apresentados em Relatório realizado pela CONTAG, a redistribuição de renda decorrente dos benefícios previdenciários rurais é relevante para a efetivação da equidade, não apenas individualmente, mas também entre os municípios brasileiros, sendo que o valor transferido monetariamente pela Previdência Social apresentou-se maior do que aquele transferido em nome do Fundo de Participação dos Municípios (FPM) (CONTAG, 2016, p. 27/31). Igualmente, estudos do IPEA já demonstraram a relação entre previdência social e desenvolvimento municipal, a partir do estímulo à economia local, principalmente nos pequenos municípios (BARBOSA, 2007, p. 240/247).

Outros estudos demonstram também que a PSER encontra-se predominantemente em municípios de pequeno porte. Segundo Ipea mais de dois terços do valor total dos benefícios rurais - R \$ 5,6 bilhões só em janeiro de 2016 - foram destinados a municípios de até 50 mil habitantes e nos municípios maiores, o valor total transferido não alcançou a metade (IPEA, 2017, p. 17).

Ademais, pesquisadores demonstram que a Previdência Social Especial também atua na redistribuição de renda de municípios mais ricos para os mais pobres, representando grande parcela do PIB de municípios mais empobrecidos e fator de dinamização de sua economia, já que se trata de um recurso que a população utiliza para viver melhor, movimentando o setor de serviços e o comércio (IPEA, 2017, p. 17/18).

$\mathrm{Na}$ medida em que os benefícios previdenciários rurais estimulam o desenvolvimento socioeconômico de vários municípios brasileiros, especialmente os 
Previdência social, desenvolvimento e soberania alimentar no campo brasileiro

pequenos e empobrecidos, cumprem um importante papel enquanto política de desenvolvimento territorial-local focada na natureza habitada, políticas estas tão raras, quase inexistentes, no Brasil ${ }^{3}$.

O relatório do CONTAG sobre a previdência social rural, publicado em 2016, a partir de dados do Ipea, indica a destinação de mais de dois terços do valor total dos benefícios rurais aos municípios até 50 mil habitantes, demonstrando ter havido, a partir disso, a injeção de R \$ 5,6 bilhões na economia desses municípios em 2016. Esses dados indicam a relevância da distribuição de renda operada pela PSER não apenas individualmente, mas também entre os municípios do país (CONTAG, 2016, p. 27).

Ou seja, a Previdência Social Especial Rural atua no desenvolvimento de pequenos municípios, na redistribuição de renda em favor de municípios empobrecidos, impede o agravamento de problemas urbanos decorrentes do êxodo rural, dinamiza economias locais e além disso propicia redução da fome e da miséria. Neste sentido, a aposentadoria rural além de garantir a proteção social dos idosos, garante o mesmo para suas famílias, atuando diretamente contra a insegurança alimentar.

A título de exemplo o relatório do CONTAG acima referenciado (CONTAG, 2016, p 29) faz referência ao município de Formosa-GO, onde a renda movimentadas pelos benefícios oriundos da previdência rural superam três vezes os repasses do Fundo de Participação dos Municípios (FPM).

Tal correlação entre desenvolvimento local e Previdência Social Especial Rural nos municípios menores, rurais e mais empobrecidos demonstra o forte impacto que esta renda representa em um cenário de base econômica ainda incipiente e mercado de trabalho pouco desenvolvido. Nesse cenário, é comum a migração do indivíduo economicamente ativo, o que contribui para o maior contingente de população idosa e explica a relevância que o benefício previdenciário de aposentadoria rural assume sobre a economia local.

Atrelado ao exposto, a Previdência Social Especial Rural também fortalece a agricultura familiar. O agricultor familiar consiste no principal beneficiário desta política social, de forma que esta favorece o setor da agricultura brasileira responsável pela produção da maior parte dos alimentos e em especial dos alimentos mais saudáveis a compor a cesta básica do brasileiro.

Assim, a Previdência Social Especial Rural consiste em política pública primordial na garantia da alimentação adequada não apenas dos seus beneficiários, mas 
também da população brasileira como um todo, e, portanto, é concretizadora do trabalho e da soberania e segurança alimentar brasileira, incentivando a extinção da desigualdade entre campo e cidade.

Ressalta-se que o direito à alimentação transcende o "comer para viver", pois é uma necessidade para a vida saudável e apropriada, que deve condizer aos aspectos culturais de cada região, aos padrões de qualidade que propiciem nutrição, segurança e prazer (MANIGLIA, 2009, p. 123).

No passado, o trabalho humano era dedicado primordialmente à tarefa de conseguir os alimentos necessários à sobrevivência. Com a divisão do trabalho e o capitalismo, o trabalho passou a significar salário, sendo este trocado por mercadorias, tal qual o alimento. Assim, alimentar-se passou a depender cada vez mais do mercado e das condições econômicas, contexto do qual surgiu o conceito de "segurança alimentar".

Tal conceito foi utilizado a partir da Primeira Guerra Mundial, com referência aos riscos da dependência alimentar em relação a outros países no contexto de guerra. Mais tarde, em 1974, o tema da fome ganhou destaque diante da iminência da escassez de produtos agropecuários. Nesse período, a "segurança alimentar" era compreendida como uma política voltada a garantir a oferta de alimentos e não como um direito humano fundamental (MANIGLIA, 2009, p. 124/126).

Em 1983, a FAO apresentou outro conceito de segurança alimentar, baseado em três objetivos, quais sejam: a oferta adequada de alimentos; estabilidade da oferta e dos mercados de alimento; e segurança no acesso aos alimentos ofertados. A partir dos anos 1990, diante das discussões sobre sustentabilidade socioambiental, o conceito passou por ressignificação englobando: “[...] noções de alimento seguro; qualidade do alimento; balanceamento da dieta; informações sobre os alimentos; opções de hábitos alimentares em modos de vida" (MANIGLIA, 2009, p. 126). Após a Conferência de Roma, em 1992, a segurança alimentar atingiu o status de um direito humano básico, a ser garantido por políticas públicas, chancelado na figura de Estado Social (MANIGLIA, 2009, p. 126).

Nos anos 2000, com a mundialização do mercado de alimentos, a segurança alimentar assumiu novos contornos. Estudiosos do tema como Sérgio Jamil Maluf vêm alertando como o comércio internacional não é fonte confiável de segurança alimentar, já que inserido no modelo dominante de produção, isto é, baseado apenas no maior crescimento possível e atrelado à exclusão de sujeitos, escassez de recursos e violências 
Previdência social, desenvolvimento e soberania alimentar no campo brasileiro

culturais (MALUF, 2007, p. 59). Ademais, cada vez mais se assenta que a fome é muito mais um problema social do que técnico.

No Brasil as primeiras referências sobre segurança alimentar datam de 1985, no âmbito do Ministério da Agricultura, sendo, a seguir, criado o Conselho Nacional de Segurança Alimentar (Consea) dirigido pelo Presidente da República. Em 1994, na 1a Conferência Nacional de Segurança Alimentar, é construído um conceito brasileiro de segurança alimentar (MANIGLIA, 2007, p. 158/160).

No governo de Fernando Henrique Cardoso o Consea foi substituído pelo Conselho da Comunidade Solidária, o qual "pretendia combater a fome e a pobreza por meio de um plano de estabilização econômica, priorizando programas e não construindo políticas". O programa Fome Zero data de 2001 e assumiu um perfil de mutirão nacional contra a fome. Em 2003 o programa "Fome Zero" foi substituído pelo "Bolsa Família", o qual unificou todos os programas sociais (MANIGLIA, 2007, p.160/161).

Quantitativamente o "Bolsa Família" teve bons resultados na melhoria alimentar da população brasileira, bem como na saúde e nível escolar das crianças, visto que impõe o cumprimento de exigências escolares e de saúde da família (2007, p. 163).

Notadamente, trata-se de estratégia imediata no combate à fome e assume importância neste aspecto da segurança alimentar. Graças a políticas desta natureza, entre 2005 e 2006, 8 milhões de brasileiros saíram da baixa renda para integrar a classe C. Avançando na promoção da segurança alimentar, em 2006 foi criada a Lei n. 11.346, de 15 de setembro de 2006, a qual cria o Sistema Nacional de Segurança Alimentar e Nutricional (Sisan), o que representou um grande passo na consagração do direito humano à alimentação. Porém, também no quadro de transferência de renda devem-se destacar os programas ligados à Previdência Social.

Os últimos anos foram primordiais para o avanço na tratativa do problema da fome no Brasil. A mudança do modelo de Estado e a ocupação do governo por grupos comprometidos com o combate da pobreza e da desigualdade social demonstraram a possibilidade de avanços na inclusão social.

Igualmente, na ordem mundial o meio ambiente e a segurança alimentar se tornam discussões de destaque, envolvendo grupos e movimentos sociais. Tais movimentos pautam a utilização do termo "soberania alimentar" a fim de dar um passo à frente na "segurança alimentar" acima mencionada, visando transcender a ideia de efetivação do direito à alimentação apenas pela distribuição de alimentos. 
A soberania alimentar diz respeito ao direito dos povos de decidir sobre o que produzir e consumir, o que envolve as condições de vida e trabalho dos agricultores e se reflete na produção de alimentos de qualidade, diversos, seguros, ambientalmente equilibrados e culturalmente adequados. O conceito ainda diz respeito à soberania alimentar nacional quanto ao consumo interno, bem como à biodiversidade e preservação de espécies tradicionais (LEÃO, 2013, p. 17).

O conceito envolve um complexo de garantias, relacionadas ao direito dos povos de definir suas políticas de agricultura, trabalho, alimentação e intervenção na natureza de maneira ecológica, social, cultural e economicamente adequadas à sua concretude. Ainda sobre a soberania alimentar, Peter Rosset (et. al.) esclarece que envolve o direito à terra, processos de reforma agrária massiva e acesso a outros recursos produtivos, como água, florestas, financiamentos, capacitação, com paridade de oportunidades para indígenas e mulheres (SAUER e PEREIRA, 2006, p. 315).

Evidentemente, a "soberania alimentar" volta-se à construção de um modelo político inovador e democraticamente avançado, com base na equânime divisão dos recursos, especialmente da terra e da água, provedoras originárias da vida. Este modelo reconhece que a mera distribuição de alimentos não é a melhor maneira a longo prazo de garantir o direito à alimentação.

A verdadeira garantia desse direito funda-se também em programas de distribuição, mas com horizonte em propostas estruturais, aptas a promover trabalho, renda e dignidade (MANIGLIA, 2009, p. 211), nesse sentido é que surge a importância de políticas como a Previdência Social Especial Rural. Agregando características de distribuição de renda, com características estruturais, a Seguridade Social, de maneira ampla, atua na concretização deste projeto vinculado à garantia do direito humano à alimentação e a dignidade de trabalhadores que muito contribuem com a sociedade e com o meio ambiente, porém que pouco recebem como remuneração.

A soberania alimentar, enquanto projeto muito à frente em termos de garantias socioambientais, para sua concretização completa deve envolver ações mais amplas do que garantias do trabalho no capital. Entretanto, é inegável, que políticas sociais já aplicadas em casos concretos, como a Previdência Social Rural no Brasil, são um passo em direção de sua viabilização, tendo em vista os impactos deste tipo de política sobre a equidade, sobre o incentivo de trabalho e produção na terra em equilíbrio com o 
Previdência social, desenvolvimento e soberania alimentar no campo brasileiro

metabolismo natural e sobre o incentivo às relações sociais e ambientais mais harmoniosas de forma geral.

A Previdência Social Especial Rural estimula os agricultores familiares, e trabalhadores rurais em sentido amplo, a permanecerem no campo e, com isso, estimula a busca por produções alternativas e reproduções socioculturais mais condizentes com a proteção da agrobiodiversidade.

Rendas e atividades não agrícolas, como é a previdência social, possuem um importante papel para a permanência da população no campo, viabilizando a agricultura familiar. Autores afirmam inclusive que os recursos previdenciários representam um tipo de "seguro-agrícola", já que possibilitam a garantia de renda constante aos trabalhadores rurais, o que é especialmente importante nos momentos de instabilidade, que poderiam ser o estopim para o abandono do trabalho no campo em direção às cidades. Ressalta-se que a instabilidade do mercado e a precariedade das políticas de apoio afeta sobremaneira as atividades agrícolas familiares e neste ramo o benefício previdenciário assume o papel não apenas de seguro de subsistência, mas também como seguro de produção familiar (CONTAG, 2016, p. 23).

Pesquisadores da área indicam também que a ampliação do acesso aos benefícios previdenciários rurais estão associados à maior permanência dos jovens no campo, o que se atrela às melhorias de renda e condições de vida propiciadas por estes benefícios (CONTAG, 2016, p. 24).

Sem dúvidas a permanência de jovens no campo, principalmente na agricultura familiar, é primordial à soberania alimentar nacional, já que possibilita a sucessão dos trabalhadores rurais, ou seja, permite que a população ativa produzindo alimentos seja ao menos mantida. Assim, indiretamente, a previdência social rural financia e incentiva as atividades produtivas no campo.

Ademais, considerando-se uma leitura sistemática da CRFB destaca-se que a universalização do acesso a direitos básicos, como as garantias à previdência social, à vida digna e à alimentação adequada, é condição indispensável à concretização de todos os direitos humanos e fundamentais, bem como pressuposto do desenvolvimento equitativo.

O caso da previdência social especial rural demonstra que o caminho do desenvolvimento rural brasileiro deve ir ao sentido de ampliar as garantias sociais, demonstrando que a proteção e o incentivo a modos de produção para além do 
hegemônico, traz efeitos positivos na inclusão de povos historicamente subalternizados e excluídos do projeto de desenvolvimento brasileiro, o que propicia efeitos positivos para a sociedade brasileira como um todo e possibilita o desenvolvimento equitativo.

Pela análise de alguns dispositivos do texto constitucional brasileiro, percebese forte contradição quando se trata da ordem econômica e do modelo de desenvolvimento nacional almejado. Entretanto, por aquela análise, demonstrou-se que é função do Estado trazer ordem e controle na confusão social ocasionada pelo modo de produção capitalista.

Conforme artigo 170, a ordem econômica brasileira, ao lado da livre iniciativa, funda-se na valorização do trabalho humano de acordo com os ditames de justiça social e deve observar o princípio da defesa do meio ambiente e da função social da propriedade. Sobre o tema bem esclarece José Afonso da Silva que a ordem econômica brasileira funda-se, ao lado da iniciativa privada, na valorização do trabalho humana, portanto trata-se de uma economia de mercado de natureza capitalista, porém com prioridade nos valores do trabalho humano sobre todos os demais. Para o autor este princípio deve orientar a intervenção do Estado, tendo em vista o fim último de assegurar a existência digna de todos, de acordo com os ditames da justiça social (2016, p. 790).

A norma estruturante do Estado brasileiro traz as bases da ideia de desenvolvimento nacional. O desenvolvimento equilibrado, nos termos da Constituição, é aquele que conjuga, conforme anteriormente abordado, geração de renda, planejamento controle da atividade econômica, bem-estar social, justiça e, muito importante, meio ambiente.

Estes preceitos básicos do Estado brasileiro sedimentam a existência de luta social pela concretização de um projeto de desenvolvimento equitativo, democrático, inclusivo, não retrocedente em termos sociais para o país. Porém, igualmente, demonstra a prevalência da livre iniciativa e da propriedade. Portanto, ao que tudo indica, a ideia de desenvolvimento nacional presente na Constituição Federal é uma representação do papel do Estado em pacificar interesses contraditórios, principalmente aqueles entre classes.

Nesse modelo sustentado pela Constituição, ainda que se mantenha o capitalismo e suas bases (livre iniciativa e a propriedade), o capital deverá abrir mão da máxima exploração do trabalhador e do meio ambiente, considerando que estes devem ser respeitados em prol da dignidade humana em última instância.

De qualquer forma, mediante tais aberturas sociais presentes na Constituição Federal, torna-se impertinente defender projeto de desenvolvimento desvinculado da 
Previdência social, desenvolvimento e soberania alimentar no campo brasileiro

proteção da natureza e do ser humano em sua dignidade. Assim, pode-se afirmar que o modelo de desenvolvimento instituído pela Carta Magna de 1988, ainda que não rompa com as bases da exploração do ser-humano e da natureza, visa impedir o retrocesso social. Nestes termos, já é sedimentado no sistema jurídico brasileiro o modelo de desenvolvimento nacional pautado na dignidade, no bem-estar social e na equidade. Estando tal modelo já concretizado não deve ser admitida a redução de garantias sociais.

A Previdência Social Especial Rural enquadra-se nesse modelo e demonstra que a melhora na qualidade de vida de todos depende da inclusão e não da restrição de direitos. Conforme demonstrado, a ampliação dos direitos dos lavradores da terra esteve associada à disputa pela ampliação do conceito de trabalhador rural, a fim de abarcar agricultores familiares, assentados, pescadores, arrendatários, entre outros. Tal ampliação permitiu além de avanço sobre o desenvolvimento equitativo nacional, nos termos constitucionalmente previstos, também o incentivo à forma de produção diferenciada e mais equilibrada socioambientalmente, representada pela agricultura familiar e/ou comunitária.

Ao incluir tais pessoas, a Previdência Social Especial Rural incentivou o tipo de relação diferenciada que estas empreendem com terra, já que não produzem mercadoria predominantemente para o mercado internacional, mas sim alimentos, que garantem a subsistência de sua família e do restante da população brasileira.

No Brasil é possível distinguir dois principais paradigmas de produção na terra. Um deles é a agricultura convencional, sinônimo de atividade comercial agrícola, que possui origens na colonização e iniciou o processo de diversificação no século XX, a partir da produção em larga escala, oferta em mercado e expansão de terras. Esse modo de produção é voltado precipuamente à comercialização para o mercado internacional, à maximização da produção e ao lucro. Como principais características podem ser citadas: - cultivo excessivo e massivo do solo; monocultura com uso abundante de venenos; irrigação constante; uso de fertilizantes; impactos negativos na biodiversidade da fauna e da flora; uso de plantas alteradas geneticamente; utilização de máquinas; utilização de trabalhador rural precarizado, sob contratação muitas vezes ilegal, em especial o boiafria.

Outra forma consiste na agricultura familiar e tradicional que se mantém com estilo próprio de cultivo. Trata-se de prática de produção realizada pelos membros da família ou comunidade tradicional ou não, que, em regra, são donos (se não, possuidores) 
da terra e dos equipamentos (comunitariamente ou individualmente). Muitas são as dificuldades destes agricultores em manter seu modo de vida, pois sobreviver à modernização massiva que ocorreu no campo brasileiro envolve vencer disputas de terra, conseguir financiamentos para investir em suas produções, entre outras dificuldades como as de comercialização.

Tendo em vista que a Previdência Social Especial Rural volta-se a esta parcela da população, além de permitir renda, qualidade de vida e inclusão social para ela (e suas consequências sociais amplas que afetam toda a população), também incentiva seus modos de produção mais equilibrados socioambientalmente (maior geração de postos de trabalho, produção de alimentos adequados ao consumo interno, práticas ambientais mais adequadas, entre outros).

Trata-se de política social consonante com a ideia de desenvolvimento nacional equitativo, constitucionalmente estabelecida, cuja supressão, total ou mesmo parcial, tende a causar impactos especialmente sobre a pobreza rural, êxodo populacional, favelização, violência urbana e soberania alimentar.

\section{CONSIDERAÇÕES CONCLUSIVAS}

A Previdência Social Especial Rural embora possua caráter de medida reformista do Estado na perpetuação de um modo de vida em crise, também constitui resultado de lutas sociais pela permanência de formas de existência historicamente suprimidas e excluídas pelo sistema hegemônico. Por isso, consideradas suas limitações quanto à transformação da realidade, é necessário levar em conta os efeitos dessa política ao viabilizar a resistência de grupos historicamente subalternizados e a esperança em movimentos democráticos de luta.

O tema tratado demonstra que, no âmbito das políticas sociais, mudanças irresponsáveis, pouco planejadas e descuidadas com o bem-estar da população tendem a levar a um cenário preocupante de desproteção social, com impactos principalmente sobre as mulheres e jovens, ensejando diversos efeitos nocivos ao desenvolvimento equitativo e ao meio ambiente como um todo.

À título de ilustração, cita-se o risco de incremento de êxodo rural; crescimento desordenado das cidades; empobrecimento de pequenos municípios; efeitos nocivos sobre o abastecimento de alimentos, e consequente esvaziamento de uma 
Previdência social, desenvolvimento e soberania alimentar no campo brasileiro

natureza atualmente habitada por sujeitos que evidenciam caminhos para o equilíbrio do metabolismo entre ser-humano e natureza.

O caso da Previdência Social Especial Rural demonstra a importância da ampliação e fomento de formas de produção racionais, visto que garantir direitos sociais aos campesinos traz efeitos positivos de forma ampla para a sociedade brasileira e possibilita o desenvolvimento equitativo. Políticas deste gênero devem ser ampliadas, rumo a um modelo de desenvolvimento socioambientalmente equilibrado, aliada ao estímulo ao modo de vida dos trabalhadores rurais, o que passa pela permanência e ampliação de conquistas sociais.

Uma crise decorrente do próprio desequilíbrio inerente ao modo de produção deve ser solucionada pela transformação do paradigma de desenvolvimento, com foco na valorização do trabalhador e da natureza e no avanço equitativo e não pela transferência dos custos para os mais fragilizados. Toda a exploração possui limites e no caso brasileiro estamos muito próximos deste, permanecer pressionando trabalhador e natureza acarretará décadas de retrocesso em poucos anos, miséria e aumento de catástrofes socioambientais.

\section{REFERÊNCIAS}

ALVIM, Ruy Carlos Machado. Uma história crítica da legislação previdenciária brasileira. Revista de Direito Previdenciário. Vol. 1, p. 11-52, nov. - dez. 2014.

BARBOSA, Rômulo Soares. Entre igualdade e diferença: processos sociais e disputas políticas em torno da Previdência Social Rural no Brasil. Tese submetida como requisite parcial para a obtenção do grau de Doutor em Ciências, no Programa de Pós-Graduação de Ciências Sociais em Desenvolvimento, Agricultura e Sociedade. Apresentação em 13/09/2007, na Universidade Federal Rural do Rio de Janeiro.

BRASIL. Constituição (1988). Constituição da República Federativa do Brasil. Brasília, DF: Senado Federal: Centro gráfico, 1988.

CASTRO, Carlos Alberto Pereira de e LAZZARI, João Batista. Manual de Direito Previdenciário. Rio de Janeiro: Editora Forense, 2016.

CARVALHO, Horácio Martins de. A Expansão do Capitalismo no Campo e Desnacionalização do Agrário no Brasil. In: Revista da Associação Brasileira de Reforma Agrária - ABRA, edição especial, Agronegócio e Realidade Agrária no Brasil, Campinas, jul - 2013.

CONTAG, FEtAGs e STTRs. Previdência Social Rural: potencialidades e desafios. Brasília: julho de 2016. 
DELGADO, Mauricio Godinho. Curso de direito do trabalho. 15. ed. São Paulo: LTr, 2016.

ESCOBAR, Arturo. Sentipensar con la tierra. Nuevas lecturas sobre desarrollo, territorio y diferencia. Colección Pensamiento Vivo. Medellín: Ediciones UNAULA, 2014.

FALEIROS, Vicente de Paula. A política Social do Estado Capitalista. São Paulo: Editora Cortez, 8ª ed., 2000.

FIAN BRASIL. Da democratização ao golpe: Avanços e retrocessos na garantia do direito humano à alimentação e à nutrição adequados no Brasil. Brasília: 2017. ISBN: 978-85-92867-02-7.

IPEA. Reforma da Previdência, Agricultura Familiar e os riscos de desproteção social. Alexandre Arvex e Marcelo Galiza. Mercado de Trabalho, Política em foco, n. 62, Brasília, abr. 2017.

ISAGUIRRE, K. \& FRIGO, D. Desenvolvimento rural, meio ambiente e direitos dos agricultores, agricultoras, povos e comunidades tradicionais. Curitiba: Terra de Direitos, 2014, 30 p.

IANNI, Octávio. A utopia camponesa (1986). In: WELCH, Clifford A.; MALAGODI, Edgard; CAVALCANTI, Josefa S. B.; WANDERLEY, Maria de N. B. (Org.) Camponeses Brasileiros: Leituras e interpretações clássicas. São Paulo; Ed.Unesp; Brasilia, DF.NEAD, 2009, p. 135-144.

LEÃO, Marília Mendonça. O direito humano à alimentação adequada e o Sistema Nacional de Segurança Alimentar e Nutricional. Brasília: ABRANDH - Ação Brasileira pela Nutrição e Direitos Humanos, 2013.

MALUF, Sérgio Jamil. Segurança alimentar e nutricional. Petrópolis: Vozes, 2007.

MANIGLIA, Elisabete. As interfaces do direito agrário e dos direitos humanos e a segurança alimentar. São Paulo: Editora UNESP; São Paulo: Cultura Acadêmica, 2009. Disponível em <http://books.scielo.org> último acesso em 08 de janeiro de 2018.

MARX \& ENGELS. O manifesto comunista. Edição eletrônica Ridendo Castigat Mores, 1999. Fonte digital.

HACON, Vanessa de Souza \& LOUREIRO, Carlos Frederico, Estruturas de poder e a questão ambiental: a reprodução da desigualdade de classe. In: Desenvolvimento e Meio Ambiente, v. 29, p. 59-69, abr. 2014.

SAUER, Sérgio e PEREIRA, João Márcio (orgs.). Capturando a terra: Banco Mundial, políticas fundiárias neoliberais e reforma agrária de mercado. São Paulo: Expressão Popular, 2006. 
Previdência social, desenvolvimento e soberania alimentar no campo brasileiro

SCOTT, James. Formas cotidianas da resistência camponesa. Raízes, v. 21, n. 1. Campina Grande, 2002. p. 10-31.

SILVA, José Afonso da. Curso de Direito Constitucional Positivo. rev. e atual. São Paulo: Malheiros, 2016.

Artigo recebido em 10 de maio de 2018 e aceito em 31 de dezembro de 2018

\footnotetext{
${ }^{1} \mathrm{O}$ índice de Gini mede a desigualdade de renda no mercado de trabalho, quanto mais próximo de 0 menor a diferença entre os menores e maiores salários. A valorização do salário mínimo ocorrida no Brasil nas últimas décadas ocorreu ao lado da redução em $70 \%$ no coeficiente de Gini.

${ }^{2}$ Segundo o Decreto 6040, que instituiu a Política Nacional de Desenvolvimento Sustentável dos Povos e Comunidades Tradicionais (PNPCT), os povos e comunidades tradicionais são definidos como "grupos culturalmente diferenciados e que se reconhecem como tais, que possuem formas próprias de organização social, que ocupam e usam territórios e recursos naturais como condição para sua reprodução cultural, social, religiosa, ancestral e econômica, utilizando conhecimentos, inovações e práticas gerados e transmitidos por tradição".

${ }^{3}$ Ainda que no Brasil existam muitas políticas de desenvolvimento rural, a grande maioria voltase no modelo hegemônico de terra mercadoria (terra vazia).
} 